\section{Calakmul, Yucatan}

FurTher particulars of the recently discovered Maya city of Calakmul, in the south of Campeche, Yucatan, dated by its sculptured monuments as belonging to the Old Empire, A.D. 364-551, have been published by the Carnegie Institution of Washington (News Service Bulletin, vol, 2, No. 34). The information is derived from a report by Dr. S. G. Morley on the results of an expedition of the Institution which left Washington for Calakmul in April last. Forty-one additional monuments were discovered, bringing the total number up to 103, the largest number yet found on any Central American site. The dates on 45 monuments have been deciphered. Among the more notable discoveries were the quarry from which the stone was taken with two large blocks side by side, partially quarried, just as they were left by the builders, a huge flat outcrop of limestone in which were sculptured figures of six prisoners with their arms tied behind them by ropes and a large sculptured monument portraying a priest grasping a spear in his right hand, which was erected in A.D. 472. Owing to the luxuriance of the vegetation only a single building has been left standing. A survey map of the central part of the site, the civic and religious centre, has been made. The importance of the site lies in the fact that, lying half way between the earlier cities of northern Guatemala and the later cities of northern Yucatan, it fills in a geographical 'blind-spot' and bridges the gap between the two regions. It is within four days' journey by mule from Uaxactun, the oldest city of the Maya civilisation in northern Guatemala. The foundation of the city, or at least its attainment of sufficient economic importance to permit the inhabitants to mark the five year periods by the erection of monuments, would appear to coincide with the later part of the First Period of the Old Empire, when Maya culture was expanding throughout the Yucatan peninsula.

\section{Paintings in Ancient Palestine}

A DIscovery of special interest at Teleilat Ghassul in Palestine is reported by the Rev. J. G. Duncan in the current issue of Ancient Egypt (Pt. 3, 1932). On this site, which is conjecturally identified with the ancient Sodom, three buildings, evidently not temples or palaces, but dwelling-houses, have been brought to light which date, at the latest, from 2,000 B.c., when the city was finally destroyed. In two of them the room-walls proved unexpectedly large, being $19 \mathrm{ft}$. and $20 \mathrm{ft}$. in length respectively. It was not known previously that dwellings of this size were in use in Palestine at this early stage of civilisation. What, however, was of even greater interest was the fact that these walls had been decorated with paintings, a single subject covering the whole wall, thus arguing developed artistic skill. With the exception of a cistern at Ophel, attributed doubtfully to the Byzantine age, wall paintings had not been discovered previously in ancient Palestine. The paintings, which are on plaster, have suffered from various causes, including the damp soil, which may explain the apparent absence of wall-paintings on excavated sites. It is just possible to make out the subject of two of the paintings. One is apparently a religious scene and shows several, six or seven, human figures gazing towards a shining object in front of which stands a smaller figure, facing the others; and the second is a landscape or hunting scene, in which the only well-preserved figure is a bird, painted with a master's touch. The colours, light and dark red, brown in various shades, black, yellow and white are the same as appear in the painted pottery. The site, which is being excavated by $P$. Mallon, is somewhat obscure in its cultural and chronological relations. It appears to be of late neolithic or early copper age date.

\section{Exhibition of Scientific Instruments and Apparatus}

A Preliminary announcement of the Physical Society's twenty-third Annual Exhibition of Scientific Instruments and Apparatus which is to be held at the Imperial College, South Kensington, on January 3-5 has already appeared in these columns (Dec. 10, p. 887). Particulars are given there of the times of opening and of the times and titles of the discourses. The catalogue of the exhibition, which is used by many as a reference book during the year, has now been published, and copies may be obtained from the Exhibition Secretary, at the office of the Society, 1, Lowther Gardens, Exhibition Road, London, S.W.7 (9d. post free). We are glad to notice that although the name of the Optical Society no longer appears on the catalogue, since it has amalgamated with the Physical Society of London, the optical instrument trade is as well represented as in former years. The Physical Society is making an important contribution to the scientific instrument trade by the inclusion of a section for apprentices and learners at the Annual Exhibition. The catalogue shows that the exhibits in the research and experimental section will be of great interest, and that the trade section, which forms the principal part of the exhibition, will include many important new developments. The value of the exhibition is enhanced by the excellent response of those taking part in it to the desire expressed by the organising committee, that the working parts of instruments or apparatus should be exposed to view. In some instances exhibitors have provided working models. We understand that the discourses to be delivered at the exhibition will be fully illustrated by experiments, lantern slides, and cinematograph films.

\section{Floodlighting}

THE floodlighting of many of London's famous buildings last year was a great popular success. It also gave engineers a unique opportunity of studying the problem critically. In a paper on the subject which appears in the General Electric Co.'s (G.E.C.) Journal for November, Mr. T. E. Ritchie begins a very thorough discussion of the subject. He shows the fallacy of thinking that floodlighting is objectionable because it is 'unnatural'. The same objection might be urged against the inside lighting or the warming of a building or even against the building

No. 3296, Vol. 130] 
itself. In many cases, however, the way in which it is done is open to severe criticism. To illustrate this he shows photographs of Thames House, Millbank, floodlighted, first when special attention is paid to the roof and skyline and secondly when they are neglected. In the first case, the effect produced is beautiful but in the second case the floodlighting is very disappointing, the building appearing dwarfed and incomplete. The floodlighting in the first case was designed by Sir Frank Baines, the architect responsible for the building, and he supervised its execution. It is also pointed out what an important part the reflection factor of the lighted portion of the front of the building plays. In floodlighting the front of the Institution of Electrical Engineers, London, for example, the aggregate total load on the 26 floodlights used is 39 kilowatts. Owing to lack of time, the front had not been steam-cleaned prior to the installation and so the average reflecting factor was only 7 per cent. If it had been steamcleaned, the average reflecting factor would have been increased about five times and so the saving, if the same total illumination were produced, would be about four-fifths of the present current bill.

\section{Electric Cooking on the Thermal Storage System}

SINCE coal can be produced at a uniform rate and stored ready for use as required, the plant necessary for its production has only to be capable of supplying the average demand. The same is true of oil and gas but not of electricity. Therefore the size of the necessary generating plant for electricity is fixed by the maximum and not by the average demand. As a rule the maximum output is about three times the average output and so most generating stations could treble their output provided the load was evenly distributed over the day and night. As capital charges usually represent an appreciable fraction of the selling price of electricity, any new demand which tends to level the load can be supplied economically at a reduced tariff. In thermal storage systems for heating buildings or for supplying hot water, use is made of this principle by supplying heat to the storage water at times of light load at a much reduced rate. In the case of electric 'cookers' using thermal storage, the problem is more difficult as the temperature required for cooking is much higher and the cost limits the use of too much thermal insulation. In an article on storage cookers in the General Electric Co.'s Journal for November, O. W. Humphreys and Dr. E. C. Walton describe different types of these devices used in America and various Continental countries as well as the 'magnet storage cooker'. Compared with the standard type of electric cooker, the latter has the following advantages. The cost of installation is very low as it is merely the cost of an extra lighting point in the house circuit. The cost of maintenance is also very low compared with the ordinary cooker, and no meter is required. When the electric supply is sufficiently cheap these cookers might well be used. Some are already in use in the Midlands in the homes of working-class people.

\section{Research in Plant Industry in Australia}

THE fifth annual report of the Australian Council for Scientific and Industrial Research shows that results of great economic value, far exceeding the total expenditure of the Council, have been achieved. Problems relating to the control of disease form one of the chief lines of investigation undertaken by the division of plant industry, and such outstanding success has been obtained in the control of bunchy top disease in bananas that it has led to the reestablishment of the crop on large areas. The heavy annual loss hitherto sustained from the development of bitter pit in exported apples should now be reduced to negligible proportions, since its relation to immaturity at picking time has been established. An additional activity of this division is the introduction from abroad of new varieties of plants likely to be of value, particularly in the drier districts. Following the success with which weed pests, such as St. John's wort, have been suppressed, the entomological division is extending the method of biological control to other noxious plants, and an appropriate insect for destroying the Noogoora burr having been recently discovered, on the completion of laboratory trials this fly will be liberated in the infested districts. The recently formed Division of Forest Products has carried out particularly valuable work on the seasoning of hard woods for the manufacture of cases, and has further devised a rapid and cheap method for treating wood to be used for butter boxes so as to avoid the development of taint, but although attention has been given mainly to problems of immediate importance, fundamental research has not been neglected.

\section{Weeds of Grassland}

IN spite of the increased attention paid to grassland farming in recent years, there is still a vast area of permanent grass of poor quality, and since the reduction of weeds is intimately associated with the best means for securing its improvement, the issue by the Ministry of Agriculture of "Weeds of Grassland" (prepared by H. C. Long, and published by H.M. Stationery Office, price 58 . net), should prove of great value. At the outset, emphasis is laid on the necessity for using clean seed when sowing land down to grass, as injurious weeds are readily introduced, and instances of the special dangers in the case of the rye-grasses and clovers are cited. The principles in eradicating weeds from grassland are those which make for general improvement in the herbage, and in many cases attention to drainage, manuring, grazing, etc., rather than direct methods of destruction (though spraying is considered), will lead to the eradication of undesirable species. A large number of the worst weeds that occur on grassland are dealt with individually, classification being made according to the natural orders to which they belong. A. short botanical description, in which technical terms are so far as possible avoided, coupled with 92 illustrations (18 of which are coloured) from seeding to fruiting stages, renders identification a comparatively simple matter, and points of interest such as the association

No. 3296, VoL. 130] 